\title{
Chronic hypoxia: A model for cyanotic congenital heart defects
}

\author{
Antonio F. Corno, MD, FRCS, FECTS ${ }^{a}$ \\ Giuseppina Milano, $\mathrm{PhD}^{\mathrm{a}}$ \\ Michele Samaja, $\mathrm{PhD}^{\mathrm{b}}$ \\ Piergiorgio Tozzi, MDa \\ Ludwig K. von Segesser, MD, FACS, FECTS ${ }^{a}$
}

See related editorials on pages 14 and 16.
From the Centre Hospitalier Universitaire Vaudois, Lausanne, Switzerland, ${ }^{\mathrm{a}}$ and University of Milan, Milan, Italy. ${ }^{\mathrm{b}}$

Received for publication May 22, 2001; revisions requested Aug 14, 2001; revisions received Sept 7, 2001; accepted for publication Oct 22, 2001.

Address for reprints: Antonio F. Corno, MD, FRCS, FECTS, Centre Hospitalier Universitaire Vaudois, 46 rue du Bugnon, CH 1011, Lausanne, Switzerland (E-mail: Antonio.Corno@chuv.hospvd.ch).

J Thorac Cardiovasc Surg 2002;124:105-12 Copyright $(9) 2002$ by The American Association for Thoracic Surgery

0022-5223/2002 \$35.00+0 $\quad \mathbf{1 2 / \mathbf { 1 } / \mathbf { 1 2 1 3 0 2 }}$

doi: $10.1067 / \mathrm{mtc} .2002 .121302$
Objective: The postoperative course of cyanotic children is generally more complicated than that of acyanotic children. A possible reason is reoxygenation injury at the beginning of cardiopulmonary bypass. In this study we tested the hypothesis that reoxygenation of chronically hypoxic hearts is worse than that of normoxic hearts.

Methods: Two groups of rats $(\mathrm{n}=9$ each) were exposed to either room air (fraction of inspired oxygen, $0.21 \%$ ) or chronic hypoxia (fraction of inspired oxygen, $0.10 \%$ ) for 2 weeks. Hearts were then isolated and perfused for 30 minutes with hypoxic buffer (oxygen saturation, 10\%), followed by 30 minutes of reoxygenation (oxygen saturation, $100 \%)$.

Results: In hypoxic rats hematocrit values, hemoglobin concentrations, and red cells were higher $(69 \% \pm 6 \%$ vs $40 \% \pm 6 \%, 219 \pm 14 \mathrm{vs} 124 \pm 12 \mathrm{~g} / \mathrm{L}$, and $10.30 \pm$ 0.6 vs $6.32 \pm 0.5 / \mu \mathrm{L} / 1000$, respectively; $P<.0001)$; the amount of ingested food was less $(22.3 \pm 4.8 \mathrm{vs} 30.7 \pm 3.9 \mathrm{~g} / \mathrm{d}, P<.001)$, as was the amount of ingested water $(21.0 \pm 3.1$ vs $50.4 \pm 14.6 \mathrm{~mL} / \mathrm{d}, P<.0001)$; and body weight was lower $(182 \pm 14.2 \mathrm{vs} 351 \pm 40.1 \mathrm{~g}, P<.0001)$, as was heart weight $(1107 \pm 119 \mathrm{vs}$ $1312 \pm 128 \mathrm{mg}, P<.005)$. The heart weight/body weight ratio was higher $(6.10 \pm$ 0.8 vs $3.74 \pm 0.1 \mathrm{mg} / \mathrm{g}, P<.0001)$. Systolic and diastolic functions, not different during the hypoxic baseline period, were more impaired in hypoxic than in normoxic hearts after the reoxygenation, whereas coronary resistance remained lower. During the hypoxic perfusion, the venous partial pressure of oxygen remained low in both groups, whereas during reoxygenation, partial pressure of oxygen was higher in hypoxic hearts, with a lower $(P<.01)$ oxygen uptake. During hypoxic baseline adenosine triphosphate turnover, lactate production and lactate turnover were lower in hypoxic hearts $(P<.005, P<.0001$, and $P<.0001$, respectively).

Conclusions: Body and blood values are severely affected by chronic hypoxia, and the cardiac effects of uncontrolled reoxygenation after chronic hypoxia are more severe than after acute hypoxia.

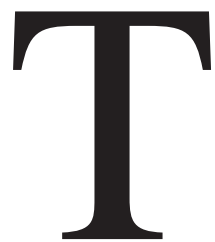

he progress in the perioperative management of pediatric patients with congenital heart defects has had a substantial effect on the outcome of surgical intervention, and a decreased mortality has been reported also for repair of complex congenital heart defects. ${ }^{1,2} \mathrm{Nev}$ ertheless, there is a subset of children undergoing cardiac surgery with higher risk for either a prolonged or complicated postoperative course: cyanotic patients with preoperative exposure to chronic hypoxia., 3

Many experimental studies have been performed to evaluate the effects of hypoxia on the cardiovascular system, but most of them, including our own, concerned exposure to acute hypoxia. ${ }^{5-7}$ Because it is evident that hypoxia produces 


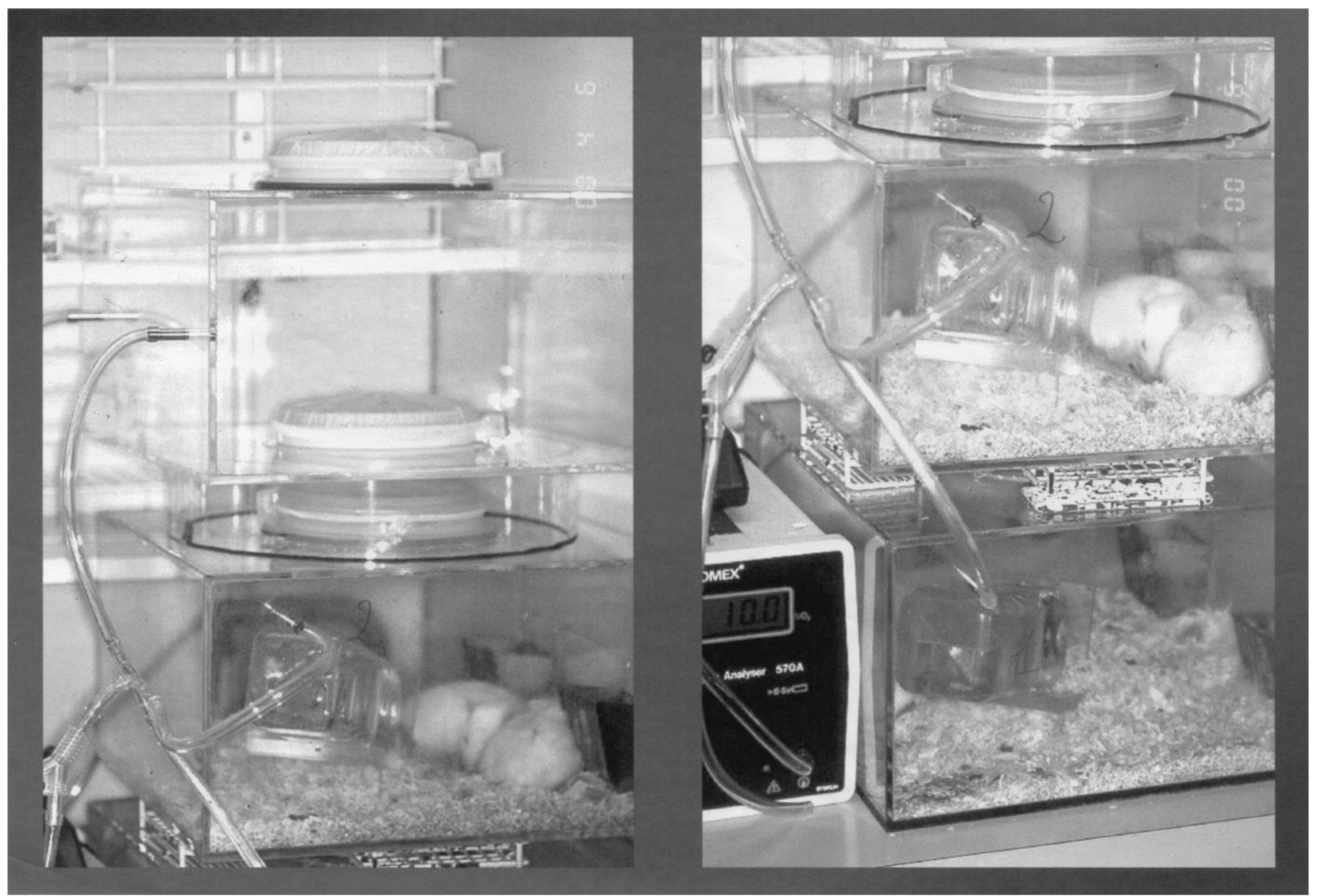

Figure 1. Photograph of the hypoxic chambers used in this study, with the saturimeter showing $10 \%$ oxygen saturation.

long-term effects that could profoundly influence the myocardial metabolism and function, ${ }^{3,8-12}$ we need studies with chronic hypoxia.

Currently, there are no models available that adequately mimic chronic perfusion of hearts with hypoxic blood. A common experimental model to evaluate the complex effects of chronic hypoxia on the cardiovascular system is raising animals in hypoxic or hypobaric chambers for extended periods of time, killing the animals, excising the hearts, and perfusing the hearts with oxygenated media. In this context, however, there are at least 2 instances in which the hearts may be suddenly reoxygenated prematurely, thereby undergoing reoxygenation injury. ${ }^{13-16}$ First, the classic design of the hypoxic or hypobaric chamber usually does not allow for daily maintenance, and therefore during feeding, as well as during cleaning, the animals are exposed to room air, with subsequent intermittent reoxygenation. Second, the hearts are generally perfused with oxygenated media to obtain baseline values; this operation implies that reoxygenation injury occurs before the baseline hypoxic values are taken.

In our previous experimental studies with acute hypoxia we demonstrated that (1) the reoxygenation of hypoxic hearts impairs the ventricular function significantly more than after ischemia-reperfusion ${ }^{6}$ and (2) the reoxygenationreperfusion injury is much more severe in hypoxic than in ischemic hearts. ${ }^{16}$ The results of our experimental studies were in agreement with the clinical observation that cyanotic patients with congenital heart defects are less tolerant to ischemia with respect to noncyanotic control subjects. ${ }^{17}$

In this experimental research we used a newly designed hypoxic chamber system, preventing any premature accidental exposure to room air and hypoxic perfusion during the initial period. The myocardial metabolism and function were monitored during the first oxygenation after a 2-week period of continuous hypoxia. The aim of our study was to evaluate the systemic and cardiac effects of chronic hypoxia and the effects of the reoxygenation on hypoxic versus normoxic hearts.

\section{Methods}

\section{Animals}

Male Sprague-Dawley rats (5 weeks old; body weight, 230-250 g at entry into the protocol) were randomly divided into 2 groups ( $\mathrm{n}=9$ per group): (1) control normoxic animals exposed to room air (fraction of inspired oxygen $\left[\mathrm{FIO}_{2}\right], 0.21$ ) and (2) chronic hypoxic animals $\left(\mathrm{FIO}_{2}, 0.10\right)$. Chronic hypoxic rats were housed in the normobaric hypoxic chambers described below for 2 weeks. All animals had free access to water and standard rat chow until 24 hours before the experiment. Water and food consumption was assessed every 2 days. The investigation conforms to the "Guide for the Care and Use of Laboratory Animals" published by the 


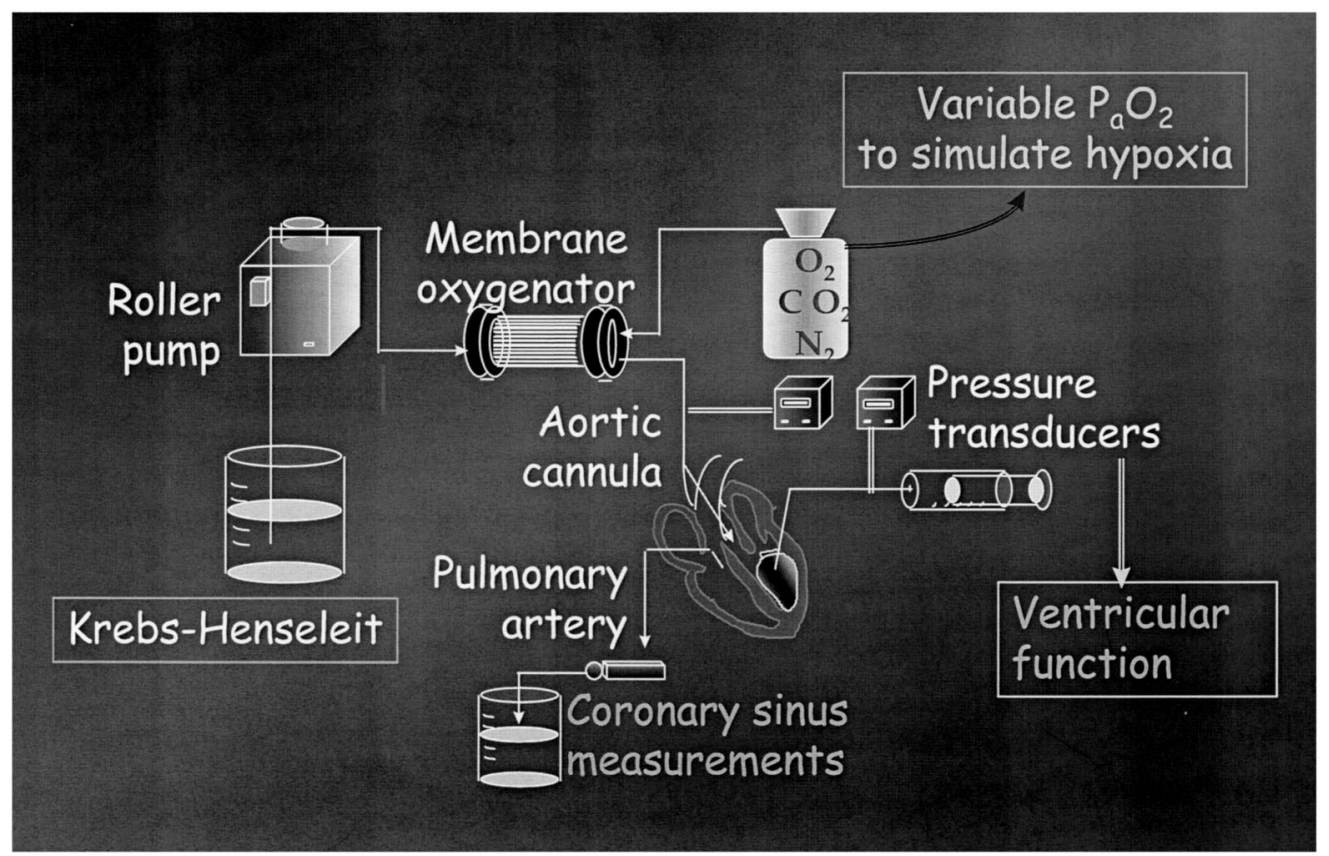

Figure 2. Schema of the Langendorff perfusion for the isolated heart with variable oxygen content.

National Institutes of Health (National Institutes of Health Publication No. 85-23, revised 1996).

\section{Cages}

The cages used in this study (Figure 1) were newly designed with the purpose of fully preventing the animals from experiencing any accidental exposure to room air $\left(\mathrm{FIO}_{2}, 0.21\right)$ during their entire stay, including during feeding and cleaning operations. Transparent plastics cages $(350 \times 350 \times 200 \mathrm{~mm})$ were built for 2 animals each to accomplish this goal. Every cage was equipped with a 165-mm diameter window with a plastic sleeve (Nufer Medical, Gumligen, Switzerland). In addition, a hole was made in the cage to allow for insertion of an oxygen electrode (Servomex Oxygen Analyzer 570 A, Zurich, Switzerland). An additional precage was built with the same dimension of the cages but with 2 windows. All cages were flushed with gas containing $10 \% \pm 0.1 \%$ oxygen (Carbagas, Lausanne, Switzerland). When a cage opening was required for regular cleaning and bed change or for operating on the animal, the precage was first flushed with the hypoxic gas, and then it was applied on the top of the cage, maintaining the 2 adjacent plastic sleeves. The operator could therefore clean the cage while avoiding animal exposure to room air. The oxygen level monitored by means of the oxygen electrode during the operation never increased by more than $1 \%$. For animal operation, the animal was first transferred into the precage under hypoxic conditions, which was then accurately closed and moved to the site where hearts were perfused. The presence of 2 plastic sleeves allowed the operator to anesthetize the animal, weigh it, and excise the heart at the same oxygen level $(10 \%)$ as that of the animals that lived inside the precage. The oxygen percentage monitored with the oxygen electrode during this phase never increased by more than $2 \%$.

\section{Heart Perfusion}

The model of Langendorff perfusion for the isolated heart with variable oxygen content (Figure 2) has been previously described in detail. ${ }^{18}$

Rats were anesthetized with intraperitoneal injection of sodium thiopental $(10 \mathrm{mg} / 100 \mathrm{~g}$ of body weight) and $500 \mathrm{U}$ of heparin. Immediately after induction of general anesthesia, a blood sample was collected from the femoral artery for blood gas analysis. Hearts were rapidly excised and immersed in $0.9 \% \mathrm{NaCl}$ at room temperature $\left(25^{\circ} \mathrm{C}\right)$. The interval between heart excision and the beginning of the perfusion was in the 30- to 45-second range. Hearts were cannulated and immediately perfused with a hypoxic Krebs-Henseleit buffer containing $2.0 \mathrm{mmol} / \mathrm{L}$ free $\mathrm{Ca}^{++}$and 11 $\mathrm{mmol} / \mathrm{L}$ glucose $(\mathrm{pH} 7.33 \pm 0.01)$ at $37^{\circ} \mathrm{C}$. In brief, a roller pump (Ismatec SA; Labortechnik-Analytik, Glattbrugg-Zurich, Switzerland) delivered the medium at a flow of $15 \mathrm{~mL} / \mathrm{min}$ to an $8-\mu \mathrm{m}$ pore size, 47-mm diameter filter (MSI, Westboro, Mass), a specially designed membrane micro-oxygenator (Dideco, Mirandola, Italy) that flowed with gas at the desired $\mathrm{Po}_{2}$, a preheater, and the aortic cannula. The coronary flow was maintained constant at 15 $\mathrm{mL} / \mathrm{min}$ throughout the entire experiment. The gas was provided from cylinders (Carbagas) containing either 10\% oxygen, $6 \%$ carbon dioxide, and $84 \%$ nitrogen or $94 \%$ oxygen and $6 \%$ carbon dioxide. The nominal accuracy was $\pm 0.01 \%$. The temperature of the heart and of the perfusion medium was maintained at $37^{\circ} \mathrm{C}$ with an external water bath. A latex balloon introduced into the left ventricle was connected to a pressure transducer (MPC-500; Millar Instruments, Inc, Houston, Tex) to monitor left ventricular performance. An additional transducer was inserted above the aortic cannula to monitor the coronary perfusion pressure. A cannula was inserted into the pulmonary artery to collect the venous return and to monitor venous $\mathrm{pH}$, as well as venous $\mathrm{Po}_{2}$, by using an oxygen- 
TABLE 1. Blood and morphologic data in the animals at the end of the 2-week exposure to normoxic (oxygen saturation, $21 \%$ ) or hypoxic (oxygen saturation, $10 \%$ ) environment

\begin{tabular}{|c|c|c|c|}
\hline & Normoxia & Chronic hypoxia & $P$ value \\
\hline No. & 9 & 9 & NS \\
\hline Initial body weight, g & $249 \pm 5.3$ & $237 \pm 5.1$ & NS \\
\hline Hematocrit, $\%$ & $40 \pm 6$ & $69 \pm 6$ & $<.0001$ \\
\hline Hemoglobin, g/L & $124 \pm 12$ & $219 \pm 14$ & $<.0001$ \\
\hline Red blood cells/ $\mu \mathrm{L} / 1000$ & $6.32 \pm 0.5$ & $10.30 \pm 0.6$ & $<.0001$ \\
\hline Ingested food, $\mathrm{g} / \mathrm{d}$ & $30.7 \pm 3.9$ & $22.3 \pm 4.8$ & $<.001$ \\
\hline Ingested water, $\mathrm{mL} / \mathrm{d}$ & $50.4 \pm 14.6$ & $21.0 \pm 3.1$ & $<.0001$ \\
\hline Final body weight, $g$ & $351 \pm 40.1$ & $182 \pm 14.2$ & $<.0001$ \\
\hline Heart weight, mg & $1312 \pm 128$ & $1107 \pm 119$ & $<.005$ \\
\hline Heart/body weight ratio, $\mathrm{mg} / \mathrm{g}$ & $3.74 \pm 0.1$ & $6.10 \pm 0.8$ & $<.0001$ \\
\hline Arterial $\mathrm{PO}_{2} \mathrm{~mm} \mathrm{Hg}$ & $58.7 \pm 5.1$ & $34.1 \pm 1.1$ & $<.005$ \\
\hline Arterial oxygen saturation, \% & $90.1 \pm 1.0$ & $43.0 \pm 3.0$ & $<.001$ \\
\hline
\end{tabular}

Data are expressed as means \pm SD. NS, Not significant.

sensing electrode (model 5300 Oxygen Monitor; Yellow Springs, Inc, Yellow Springs, Ohio).

\section{Measurements of Myocardial Function and Metabolism}

Myocardial performance was monitored with a LabView system (National Instruments, Austin, Tex) running on a personal computer. The measured parameters included left ventricular enddiastolic pressure (LVEDP), heart rate (HR), left ventricular developed pressure (LVDP), coronary perfusion pressure (CPP), and oxygen uptake $\left(\mathrm{VO}_{2}\right)$, which was calculated from venous $\mathrm{PO}_{2}$ and coronary flow. The coronary vascular resistance was calculated as CPP-LVEDP per flow per gram of ventricle. Samples of the venous effluent were frozen at $-80^{\circ} \mathrm{C}$ and later assayed for lactate by means of enzymatic methods with COBAS FARA II (HoffmanLa Roche, Basel, Switzerland) equipment.

Simultaneous measurements of lactate release and venous $\mathrm{PO}_{2}$, together with glucose as the only substrate, allows estimating the anaerobic and aerobic contributions to total adenosine triphosphate (ATP) turnover:

$$
\text { Lactate release }+\left(6 \times \mathrm{Vo}_{2}\right)^{6}
$$

For this, we assumed the ATP/lactate ratio to be \pm 1.0 (glucose as substrate without significant glycogenolysis) and the ATP/oxygen ratio to be 6 (no mitochondrial uncoupling).

\section{Experimental Protocol}

All hearts were subjected to 30 minutes of hypoxic perfusion with $15 \mathrm{~mL} / \mathrm{min}$ coronary flow and $10 \%$ oxygen saturation. During the hypoxic period, the intraventricular balloon volume needed to increase the LVEDP from 0 to $10 \mathrm{~mm} \mathrm{Hg}$ was measured. The balloon volume was kept constant throughout the rest of the experiment. After the hypoxic perfusion, hearts were reoxygenated for 30 minutes with the perfusion medium at $100 \%$ oxygen saturation. At the end of the perfusion, the hearts were weighed.

\section{Statistics}

Data are expressed as means $\pm \mathrm{SD}$.

\section{Results}

\section{Animal Homeostasis}

Table 1 shows the changes induced by 2 weeks of chronic hypoxia. Hematocrit values, hemoglobin concentrations, and red blood cell counts were higher $(P<.0001)$ in hypoxic than in normoxic rats. The amount of ingested food was less $(P<.001)$, as was the amount of ingested water $(P<.0001)$, in hypoxic rats. The body weight was lower $(P<.0001)$, as was the heart weight $(P<.005)$. The heart weight/body weight ratio was higher $(P<.0001)$, whereas the intraventricular balloon volume needed to increase LVEDP from 0 to $10 \mathrm{~mm} \mathrm{Hg}$ remained essentially constant in both groups.

Of course, there was a significant difference between the 2 groups with regard to the arterial $\mathrm{Po}_{2}(P<.005)$ and oxygen saturation $(P<.001)$.

\section{Myocardial Function}

Systolic function. During the hypoxic baseline perfusion, there was no difference between the 2 groups with regard to HR, LVDP, and HR $\times$ LVDP. During reoxygenation, HR and LVDP increased in both groups, but more in the normoxic group, leading to a significant difference $(P<$ $.05)$ between the 2 groups for the HR $\times$ LVDP product (Figure 3, A).

Diastolic function. Because LVEDP was fixed at the beginning of the perfusion, there was no difference between the 2 groups during the hypoxic baseline period. At the end of reoxygenation, LVEDP was lower $(P<.01)$ in normoxic than in hypoxic hearts (Figure $3, B$ ). CPP and coronary vascular resistance were significantly higher $(P<.001$ and $P<.05$, respectively) in normoxic hearts at the beginning of the hypoxic stabilization, as well as at the end of reoxygenation (Figure 3,C). 

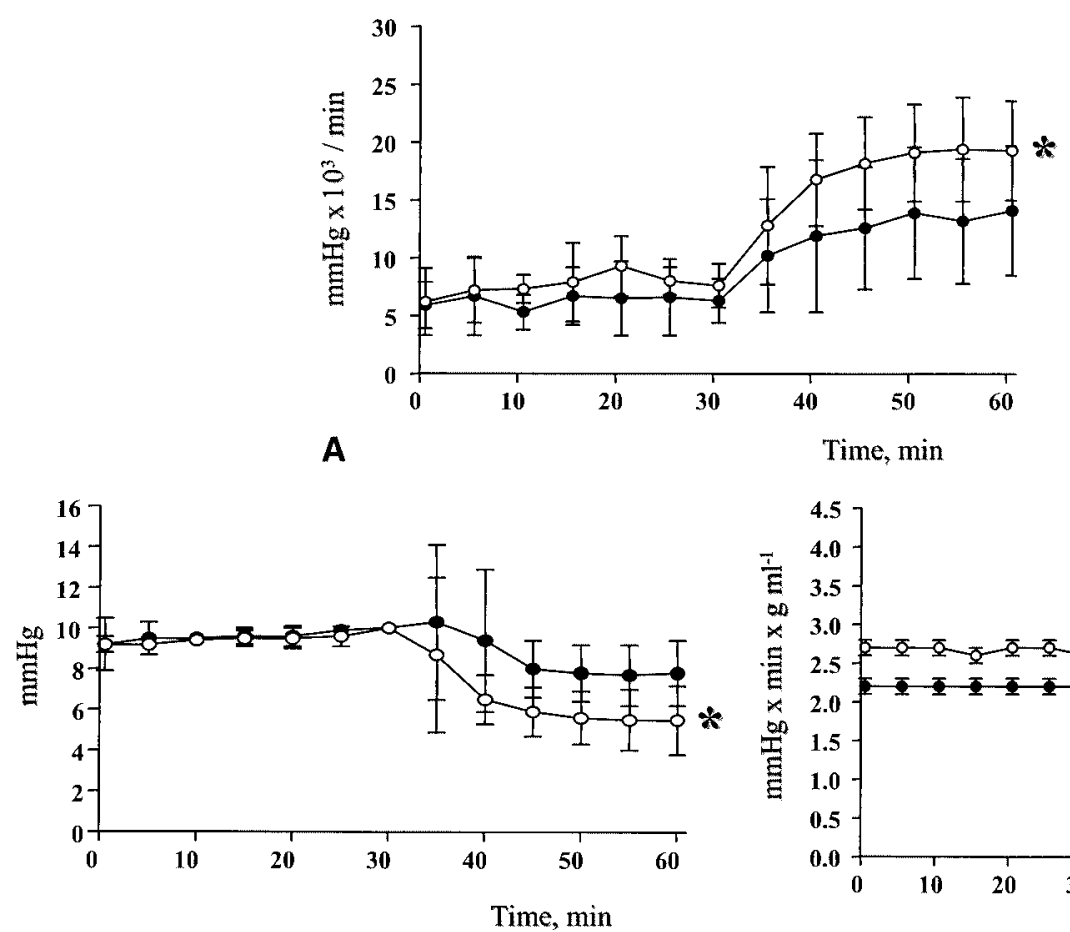

B

Time, $\min$

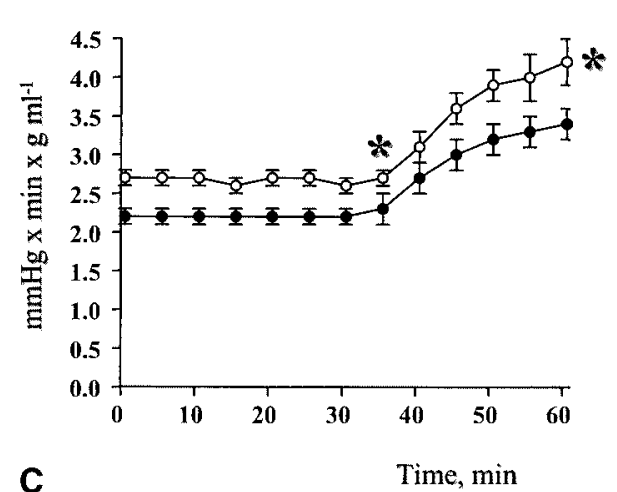

Figure 3. Time course of the HR $\times$ LVDP product (A), LVEDP (B), and coronary vascular resistance (C) during the first 30 minutes of the hypoxic baseline period (oxygen saturation, 10\%), followed by 30 minutes of reoxygenation (oxygen saturation, 100\%). A and $C,{ }^{*} P<.05 ; B,{ }^{*} P<.01$.

\section{Myocardial Metabolism}

Although, during the hypoxic baseline period, the venous $\mathrm{PO}_{2}$ remained low in both groups, during reoxygenation, it was higher in hypoxic hearts, showing a significantly $(P<$ .01 ) lower oxygen uptake in this group (Figure $4, A$ ). During hypoxic baseline lactate production, lactate turnover and ATP turnover were higher in normoxic hearts $(P<.0001$, $P<.0001$, and $P<.005$, respectively; Figure $4, B-D$ ), whereas during reoxygenation, lactate was undetectable in both groups.

\section{Discussion}

Hypoxic states of the cardiovascular system, which are associated with the most frequent diseases of modern times, originate from the imbalance between the amount of oxygen supplied to the cardiac cell and the amount required. The degree of hypoxic injury depends not only on the intensity and duration of the hypoxic stimulus but also on the cardiac tolerance to oxygen deprivation. This variable changes significantly during phylogenetic and ontogenetic development. The heart of an adult poikilotherm is significantly more resistant compared with that of the homeotherm. Similarly, the immature homeothermic heart is more resistant than the adult homeothermic heart, possibly as a consequence of its greater capability for anaerobic glycolysis.

Children with cardiac malformations are often cyanotic, and the surgical intervention for cyanotic congenital heart defects is hindered by greater mortality and morbidity than in the corresponding treatment in noncyanotic hearts. ${ }^{4,17}$ This feature may arise from the injury induced by acute reoxygenation at the onset of cardiopulmonary bypass, ${ }^{13-16,19}$ with free radicals as a major mediator in the hypoxiareoxygenation injury. ${ }^{13,16}$

Despite the fact that the vast majority of experimental studies, including ours, ${ }^{5-7}$ have evaluated the effects of acute hypoxia on the cardiovascular system, within the last few years, an increasing number of studies concerned chronic hypoxia, ${ }^{8,9,11,12,20}$ and it is now evident that hypoxia produces long-term effects that could profoundly influence the myocardial metabolism and function. ${ }^{3,8-12}$

To perform the functional and metabolic evaluation, we used the conventional Langendorff model of the isolated perfused heart, with its well-known advantages and limits. ${ }^{18}$ Recently, a very promising mathematic model to study the cardiovascular effects of hypoxia has been presented and validated..$^{21}$

\section{Animal Homeostasis}

In this study exposure to normobaric chronic hypoxia induced profound changes in the blood oxygen transport characteristics. The selected $\mathrm{FIO}_{2}$ for chronic hypoxia would yield a $\mathrm{PaO}_{2}$ of $45 \mathrm{~mm} \mathrm{Hg}$, which is equivalent to $5500 \mathrm{~m}$ 

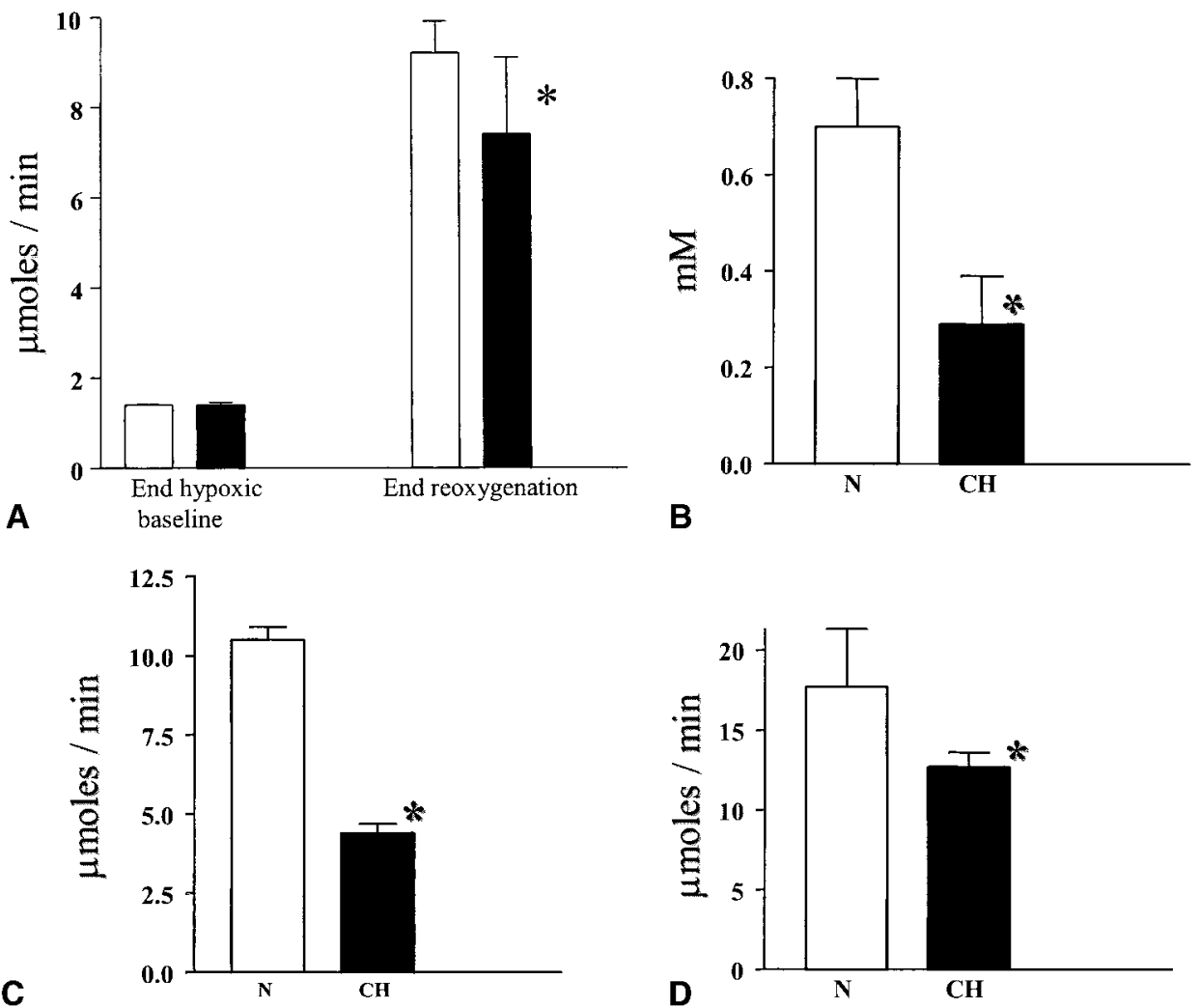

Figure 4. Metabolic parameters at the end of the hypoxic baseline period (oxygen saturation, 10\%) with the values for oxygen uptake (A), lactate production (B), lactate turnover (C), and ATP turnover (D). A, ${ }^{*}<<.01$, normoxia versus chronic hypoxia; $B$ and $C,{ }^{*} P<.0001 ; D,{ }^{*} P<.005$.

above sea level and not substantially different from the $\mathrm{PaO}_{2}$ of most children with cyanotic congenital heart defects. The increase in hematocrit values, hemoglobin concentration, and red blood cell count, common findings in all experimental and clinical studies with chronic hypoxia, is a wellknown consequence of increased hypoxia-induced erythropoietin production. $^{20,22}$

Because all rats entered the protocol at 5 weeks of age, normoxic rats experienced physiologic net weight gain over 2 weeks $(+102 \pm 13 \mathrm{~g})$. Despite unlimited access to food and water, hypoxia-induced deterioration was more powerful than the physiologic net weight gain in hypoxic rats, which underwent weight loss $(-55 \pm 9 \mathrm{~g})$; this is similar to the situation seen in adult human subjects exposed to high altitude for variable periods and to that in children with cyanotic congenital heart defects. The weight change did not correlate with the amount of ingested food, indicating greater efficiency in food consumption in normoxic than in hypoxic animals. ${ }^{12}$

The higher ratio between heart weight and body weight observed in hypoxic rats indicates ventricular hypertrophy, probably as a result of hypoxia-induced expression of several growth factors, including the vascular endothelial growth factor, as well as of increased systemic and vascular resistance caused by the higher hematocrit value. ${ }^{23}$

\section{Myocardial Function}

Although both systolic and diastolic functions were the same in the 2 groups during the hypoxic baseline period, the reoxygenation induced different behavior. The hearts from hypoxic animals appear more vulnerable than normoxic hearts to a sudden increase of oxygen supply after a short period of oxygen shortage. Possibly the decreased ventricular compliance and impaired contractility are due to the hypoxia-induced calcium load, which is further increased by the sudden reoxygenation. In this regard, we demonstrated, in previous studies, the occurrence of reoxygenation injury within the first few minutes of full oxygen readmission, ${ }^{15}$ as well as the possibility of reducing the reoxygenation injury by reducing the rate of reoxygenation, ${ }^{14}$ as routinely performed in our clinical practice. ${ }^{24}$

Reduced coronary vascular resistance in hypoxic hearts during the hypoxic perfusion, as well as during the reoxygenation, shows that chronic hypoxia induces coronary vasodilation. The increased coronary flow with acute oxygen shortage has already been reported. ${ }^{20}$ In our previous ex- 
perimental studies with acute hypoxia, the coronary blood flow increased up to $600 \%$ of baseline values during the period of oxygen shortage, with a value remaining higher than that at baseline $(>200 \%)$, even during the entire period of reoxygenation. ${ }^{25}$ The effect of coronary vasodilation with hypoxia, probably mediated by nitric oxide release, ${ }^{9,23,26}$ in the present model could have been exaggerated by the sudden decrease of the viscosity of coronary perfusion, which is more important in hypoxic polyglobulic than in normoxic hearts, because of our use of crystalloid solution for heart perfusion.

\section{Myocardial Metabolism}

During the hypoxic baseline period, hearts extracted all the oxygen available, as from the very low venous $\mathrm{Po}_{2}$. Despite a similar performance, hearts recruited their anaerobic capacities to a different extent. The contribution of anaerobic mechanisms to total ATP turnover during the hypoxic baseline period, which was higher in hypoxic than in normoxic hearts, confirms that chronic hypoxia induces different degrees of hypoxic adaptation. In reoxygenated hearts lactate release was virtually undetectable, and therefore we speculated that hearts had to completely rely on aerobic metabolism. Lack of correlation between ATP turnover and performance indicates that the efficiency of energy production is different in the 2 groups because of increased activation of the mitochondrial $\mathrm{K}_{\mathrm{ATP}}$ channels, probably the result of increased intracellular lactate, ${ }^{27}$ or because of mitochondrial damage induced by reoxygenation. ${ }^{28}$ Our data confirm the results of clinical studies on children with cyanotic congenital heart defects showing a direct correlation between the bioenergetics (ATP levels) and myocardial performance. ${ }^{4,17}$

\section{Limits of the Model}

One limit of our model is that animals entered the protocol at 5 weeks of age, whereas children with cyanotic congenital heart defects have generally been cyanotic since birth and have never been exposed to normoxia. It is true that the effect of normoxia for a certain period of time before chronic hypoxia has not yet been clarified. Nevertheless, it is well known to surgeons regularly involved with cyanotic congenital heart defects that in clinical practice there are examples of children with tetralogy of Fallot and with congenital heart defects with ductus-dependent pulmonary blood flow who are acyanotic at birth but become cyanotic later in life in correspondence, respectively, of the first hypoxic spell and of the ductal closure.

As a matter of fact, there are recent reports of experimental studies with pregnant guinea pigs ${ }^{29}$ or rats ${ }^{30}$ exposed to chronic hypoxia; unfortunately, the interpretation of the results provided by these studies must take into account the intermittent reoxygenation of the neonate animals when exposed to room air for feeding and maintenance, which is exactly what we wanted to avoid by creating our new system of hypoxic cages.

Another limit is the type of chronic hypoxia with environmental hypoxia. Other authors reported experimental studies using surgical models to induce central cyanosis, which is similar to the situation found with cyanotic children. ${ }^{3,10,30}$ Certainly the surgical models used in $\operatorname{dogs}^{3,10}$ or lambs ${ }^{31}$ are not reproducible in a rat model.

\section{Conclusion}

Our experimental model allows the evaluation of the negative systemic and cardiac effects of chronic hypoxia and the myocardial impairment caused by uncontrolled reoxygenation of hypoxic hearts. Alternative strategies of reoxygenation at the beginning of cardiopulmonary bypass should be considered for children with cyanotic congenital heart defects.

We thank Dideco, Mirandola, Italy, for kindly providing us with the micro-oxygenators used in this experimental study.

\section{References}

1. Cohen DM. Surgical management of congenital heart disease in the 1990s. Am J Dis Child. 1992;47:398-403.

2. Corno AF. Surgery for congenital heart disease. Curr Opin Cardiol. 2000;15:238-43.

3. Silverman NA, Kohler J, Levitsky S, Pavel DG, Fang RB, Feinberg H. Chronic hypoxemia depresses global ventricular function and predisposes the depletion of high-energy phosphates during cardioplegic arrest: implications for surgical repair of cyanotic congenital heart defects. Ann Thorac Surg. 1984;37:304-8.

4. Najm HK, Wallen WJ, Belanger MP, Williams WG, Coles JG, Van Arsdell GS, et al. Does the degree of cyanosis affect myocardial adenosine triphosphate levels and function in children undergoing surgical procedures for congenital heart disease? J Thorac Cardiovasc Surg. 2000;119:515-24.

5. Corno AF, Laks H, Davtyan HG, Flynn WM, Clayton CJ, Drinkwater DC. Acute hypoxia: effects on isolated neonatal heart [abstract]. Clin Res. 1986;3:5A

6. Corno AF, Motterlini R, Brenna L, Santoro F, Samaja M. Ischaemia/ reperfusion in the posthypoxaemic re-oxygenated myocardium: haemodynamic study in the isolated perfused rat heart. Perfusion. 1993; 8:113-8.

7. Samaja M, Casalini S, Allibardi S, Corno AF, Chierchia S. Regulation of bioenergetics in $\mathrm{O}_{2}$-limited isolated rat hearts. J Appl Physiol. 1994;77:2530-6.

8. Baker JE, Boerboom LE, Olinger GN. Tolerance of the developing heart to ischemia: impact of hypoxemia from birth. Am J Physiol. 1995;268:H1165-73.

9. Baker JE, Holman P, Kalyanaraman B, Griffith OW, Pritchard KA. Adaptation to chronic hypoxia confers tolerance to subsequent myocardial ischemia by increased nitric oxide production. Ann N Y Acad Sci. 1999;874:236-53.

10. Lupinetti FM, Wareing TH, Huddleston CB, Collins JC, Boucek RJ, Bender HW, et al. Pathophysiology of chronic cyanosis in a canine model. Functional and metabolic response to global ischemia. $J$ Thorac Cardiovasc Surg. 1985;90:291-6.

11. Plunkett MD, Hendry PJ, Anstadt MP, Camporesi EM, Amato MT, St Louis JD, et al. Chronic hypoxia induces adaptive metabolic changes in neonatal myocardium. J Thorac Cardiovasc Surg. 1996;112:8-13. 
12. Sekhon HS, Thurlbeck WM. Lung growth in hypobaric normoxia, normobaric hypoxia, and hypobaric hypoxia in growing rats. I. Biochemistry. J Appl Physiol. 1995;78:124-31.

13. Guarnieri C, Flamigni F, Caldarera CM. Role of oxygen in the cellular damage induced by re-oxygenation of hypoxemic hearts. $\mathrm{J} \mathrm{Mol} \mathrm{Cell}$ Cardiol. 1980;12:797-808.

14. Corno AF, Samaja M, Casalini S, Allibardi S. The effects of the rate of reoxygenation on the recovery of hypoxemic hearts. J Thorac Cardiovasc Surg. 1995;109:1250-1.

15. Corno AF, Milano G, Samaja M, von Segesser LK. Myocardial damage induced by uncontrolled reoxygenation. Asian Cardiovasc Thorac Ann. 2000;8:34-7.

16. Samaja M, Motterlini R, Santoro F, Dell'Antonio G, Corno AF. Oxidative injury in reoxygenated and reperfused hearts. Free Radic Biol Med. 1994;16:255-62.

17. del Nido PJ, Mickle DAG, Wilson GJ, Benson LN, Weisel RD, Coles $\mathrm{JG}$, et al. Inadequate myocardial protection with cold cardioplegic arrest during repair of tetralogy of Fallot. J Thorac Cardiovasc Surg. 1988;95:223-9.

18. Samaja M, Corno AF. The isolated perfused rat heart as experimental model to assess the genesis of myocardial reoxygenation injury. Cardiovasc Eng. 1998;3:120-6.

19. Matheis G, Tixier DB, Buckberg GD, Ihnken K, Morita K, Sherman $\mathrm{MP}$, et al. Cardiopulmonary dysfunction produced by reoxygenation of immature hypoxemic animals supported by cardiopulmonary bypass. J Thorac Cardiovasc Surg. 1993;105:513-9.

20. Endoh H, Kaneko T, Nakamura H, Doi K, Takahashi E. Improved cardiac contractile functions in hypoxia-reoxygenation treated with low concentration Co(2+). Am J Physiol Heart Circ Physiol. 2000; 279:H2713-9.

21. Ursino M, Magosso E. Acute cardiovascular response to isocapnic hypoxia. I. A mathematical model. II. Model validation. Am J Physiol Heart Circ Physiol. 2000;279:H149-75.
22. Gassmann M, Wenger RH. HIF-1, a mediator of the molecular response to hypoxia. News Physiol Sci. 1997;12:214-8.

23. Ozaki M, Kawashima S, Yamashita T, Ohashi Y, Rikitake Y, Inoue N, et al. Reduced hypoxic pulmonary vascular remodeling by nitric oxide from the endothelium. Hypertension. 2001;37:322-7.

24. Corno AF, da Cruz E, Lal A, Milella L, Wilson N. "Controlled reoxygenation" for cyanotic patients. In: Imai Y, Momma K, editors. Proceedings of 2nd World Congress of Pediatric Cardiology and Cardiac Surgery. Armonk, NY: Futura Publishing Co; 1998. p. 1127-9.

25. Corno AF. Evaluation of resting coronary blood flow and coronary blood flow reserve in infants after cardiac operations. J Thorac Cardiovasc Surg. 1998;116:182-3.

26. Baker JE, Contney SJ, Singh R, Kalyanaraman B, Gross GJ, Bosnjak ZJ. Nitric oxide activates the sarcolemmal K(ATP) channel in normoxic and chronically hypoxic hearts by a cyclic GMP-dependent mechanism. J Mol Cell Cardiol. 2001;33:331-41.

27. Eells JT, Henry MM, Gross GJ, Baker JE. Increased mitochondrial $\mathrm{K}$ (ATP) channel activity during chronic myocardial hypoxia: is cardioprotection mediated by improved bioenergetics? Circ Res. 2000; 87:915-21.

28. Bolling KS, Halldorsson A, Allen BS, Rahman S, Wang T, Kronon M, et al. Prevention of the hypoxic reoxygenation injury with the use of a leukocyte-depleting filter. J Thorac Cardiovasc Surg. 1997;113:1081-90.

29. Thompson LP, Aguan K, Pinkas G, Weiner CP. Chronic hypoxia increases the NO contribution of acetylcholine vasodilation of the fetal guinea pig heart. Am J Physiol Regul Integr Comp Physiol. 2000;279: R1813-20.

30. Xiao D, Ducsay CA, Zhang L. Chronic hypoxia and developmental regulation of cytochrome c expression in rats. J Soc Gynecol Investig. 2000;7:279-83.

31. Fujiwara T, Kurtts T, Anderson W, Heinle J, Mayer JE. Myocardial protection in cyanotic neonatal lambs. J Thorac Cardiovasc Surg. 1988;96:700-10.

\section{Authoritative}

The Journal of Thoracic and Cardiovascular Surgery is the most frequently cited thoracic/cardiovascular surgery journal in the Science Citation Index. An article in JTCVS is sited on average almost twice as often as those in the closest cardiothoracic journal. 